\title{
BMJ Open Marriage-based pilot clean household fuel intervention in India for improved pregnancy outcomes
}

\author{
Ajay Pillarisetti (D) , ${ }^{1}$ Sudipto Roy, ${ }^{2}$ Nadia Diamond-Smith (D) ${ }^{3}$ \\ Makarand Ghorpade, ${ }^{2}$ Arun Dhongade, ${ }^{2}$ Kalpana Balakrishnan, ${ }^{4}$ \\ Sankar Sambandam, ${ }^{4}$ Rutuja Patil (D) , ${ }^{2}$ David I Levine, ${ }^{5}$ Sanjay Juvekar, ${ }^{2,6}$ \\ Kirk R Smith ${ }^{7}$
}

To cite: Pillarisetti A, Roy S, Diamond-Smith $\mathrm{N}$, et al. Marriage-based pilot clean household fuel intervention in India for improved pregnancy outcomes. BMJ Open 2020;10:e044127. doi:10.1136/ bmjopen-2020-044127

- Prepublication history and supplemental material for this paper are available online. To view these files, please visit the journal online (http://dx.doi. org/10.1136/bmjopen-2020044127).

Received 24 August 2020 Revised 26 August 2020 Accepted 27 August 2020
Check for updates

(c) Author(s) (or their employer(s)) 2020. Re-use permitted under CC BY-NC. No commercial re-use. See rights and permissions. Published by BMJ.

For numbered affiliations see end of article.

Correspondence to

Dr Ajay Pillarisetti;

ajaypillarisetti@gmail.com

\section{ABSTRACT}

Introduction Health interventions often target pregnant women and their unborn children. Interventions in rural India targeting pregnant women, however, often do not cover the critical early windows of susceptibility during the first trimester and parts of the second trimester. This pilot seeks to determine if targeting newlyweds could protect entire pregnancies with a clean stove and fuel intervention. Methods We recruited 50 newlywed couples who use biomass as a cooking fuel into a clean cooking intervention that included a liquefied petroleum gas (LPG) stove, two gas cylinders, a table to place the stove on and health education. We first evaluated whether community health workers in this region could identify and recruit couples at marriage. We quantified how many additional days of pregnancy could be covered by an intervention if we recruited at marriage versus recruiting after detection of pregnancy.

Results On average, we identified and visited newlywed couples within 40 (SD 21) days of marriage. Of the 50 couples recruited, 25 pregnancies and 18 deliveries were identified during this 1-year study. Due to challenges securing fuel from the LPG supply system, not all couples received their intervention prior to pregnancy. Regardless, couples recruited in the marriage arm had substantially more days with the intervention than couples recruited into a similar arm recruited at pregnancy (211 SD 46 vs 120 SD 45). At scale, a stove intervention targeting new marriages would cover about twice as many weeks of first pregnancies as an intervention recruiting after detection of pregnancy. Conclusions We were able to recruit in early marriage using existing community health workers. Households recruited early in marriage had more days with clean fuel coverage than those recruited at pregnancy. Our findings indicate that recruitment at marriage is feasible and warrants further exploration for stove and other interventions targeting pregnancy-related outcomes.

\section{INTRODUCTION}

Many interventions have addressed behavioural, nutritional and environmental risk factors hypothesised to affect pregnancy outcomes. For example, in South Asia, several food or micronutrient supplement
Strengths and limitations of this study

- This is one of the first evaluations of recruitment at marriage for a clean energy intervention.

- Using community health workers, we were able to recruit couples to participate shortly after marriage.

- Recruitment at marriage, as opposed to pregnancy, leads to more days of potential coverage with an intervention and may be a useful strategy for a wide array of household-level interventions.

- This pilot study has a small sample size and reports results from one rural district in one part of Maharashtra, India.

- Exclusive use of the clean cooking intervention was low, indicating that additional behaviour change and/or economic incentives may be needed to drive usage.

programmes $^{1-3}$ and educational and communications programmes target maternal and child health behaviours and outcomes. ${ }^{4-6}$ In general, these programmes and policies have recruited women through active pregnancy surveillance or through passive surveillance by the local public health system. It is difficult, however, to identify and confirm a pregnancy at less than 8 weeks. As most women do not present at health facilities early in pregnancy due to cultural practices or lack of awareness, most pregnancies are identified later. ${ }^{7}$ Thus, interventions often cannot be introduced until near the end of the first trimester (or later). Unfortunately, many risk factors harm the fetus and mother during the first trimester. ${ }^{1}$

One such risk factor is air pollution, which can lead to a range of adverse pregnancy outcomes. $^{8-12}$ A mother's air pollution exposure during the first trimester is at least as important as exposures in later trimesters. ${ }^{11}$ The ill effects of early exposure also appear to hold for household air pollution from the 
use of solid fuels (such as wood, dung, crop residues and coal) ${ }^{8}$ Unfortunately, clean fuel interventions seeking to improve pregnancy outcomes have, to date, recruited women late in the first trimester. ${ }^{13-15}$ They thus do not protect the women and their child for as much as onethird of pregnancy.

Strategies for improving nutrition or other health outcomes preconception are not well studied. A number of papers have highlighted the importance (and challenges) of developing and integrating interventions prior to conception for improving maternal and child health. ${ }^{16-21}$ Aside from a few nutrition programmes, however, few interventions have intervened before pregnancy ${ }^{22}$-none addressing issues of household air pollution, to the best of our knowledge.

In many rural low-resource settings, most women become pregnant soon after marriage. Thus, beginning interventions at the time of marriage is a promising approach to cover the first months of a pregnancy. For example, the most recent Indian National Family Health Survey Data (2016) found that $49.6 \%$ of surveyed women were pregnant within the first year of marriage, with almost $22 \%$ giving birth within 1 year. ${ }^{7}$ Thus, one way to target the first months of a pregnancy is to identify newly married couples. One intervention in India that did target newly married couples provided these couples with information about family planning and delaying the first birth, leading to an increase in family planning uptake. ${ }^{23}$

We report on a pilot study that intervenes with a clean cooking fuel, liquefied petroleum gas (LPG), among 50 newly married, biomass-using women in rural Maharashtra, India. We first evaluate methods for and the feasibility of recruiting soon after marriage in rural Maharashtra and contribute to the evidence for this specific population on time to pregnancy after marriage. Our main outcome is days of coverage with the intervention. We compare our findings with a similar intervention (previously reported in Pillarisetti et al that targeted pregnant women in the same area at the same time. We calculate the added days of pregnancy covered by the intervention and the number of households that receive the intervention but did not get pregnant during our study. Finally, we also report days with exclusive usage or with any usage of LPG.

\section{METHODS}

\section{Study site}

We conducted the intervention in Junnar Block of Pune district, about $90 \mathrm{~km}$ north of Pune city, in the state of

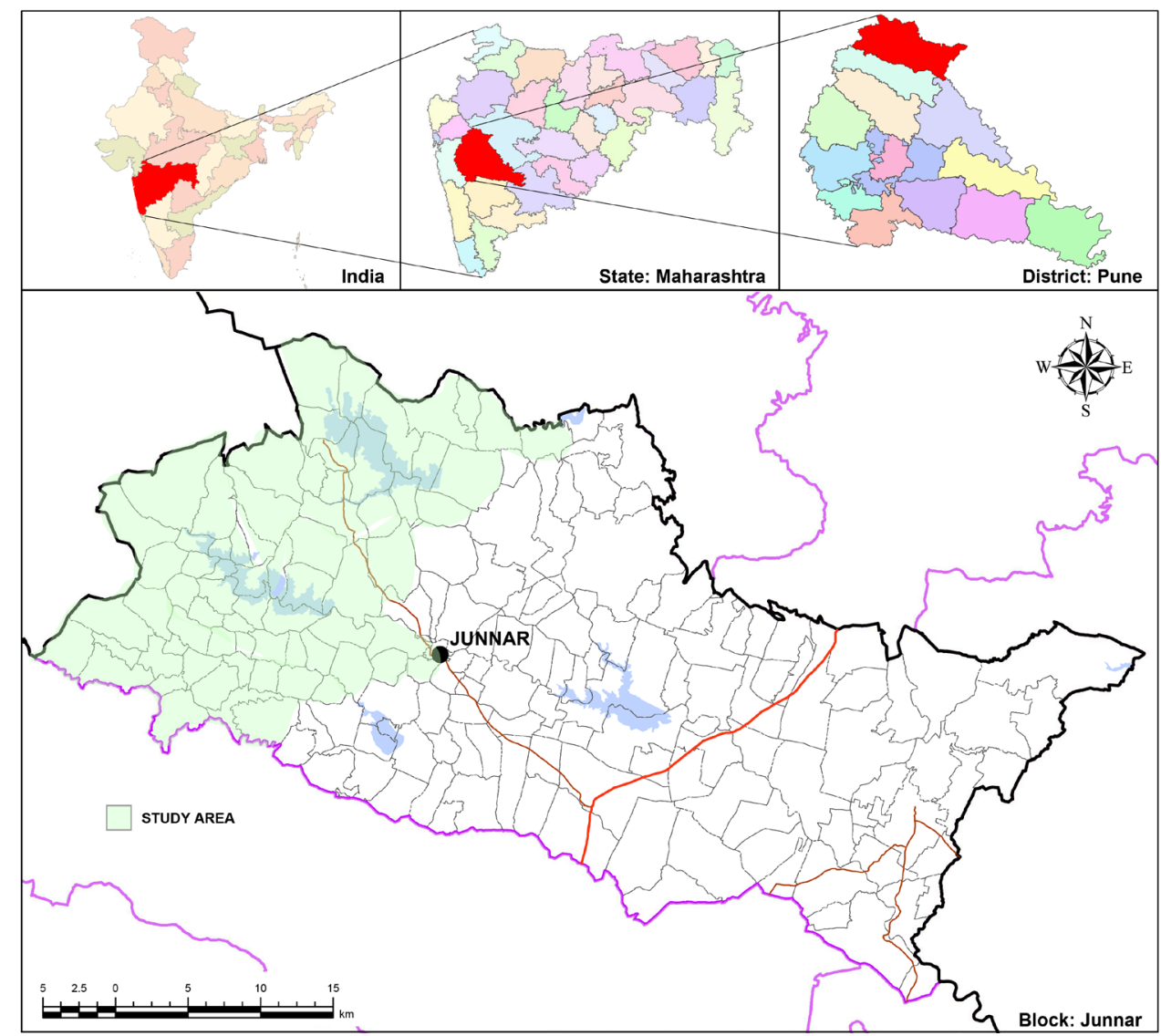

Figure 1 Map of the study site. The state of Maharashtra is located in the centre of western India. Junnar block is located in the district of Pune, approximately $90 \mathrm{~km}$ north of the city of Pune and $150 \mathrm{~km}$ east of the city of Mumbai. The filled in black circle indicates the location of the study's field headquarters; the shaded area is the region from which marriages were recruited. Map adapted from Maharashtra Remote Sensing Applications Centre (mrsac.gov.in). 
Maharashtra (figure 1), India. This predominantly tribal area lies within the western Ghats and is largely agricultural, with rice, vegetable and fruit production. In addition to using biomass for cooking, most households heat bath water every day with biomass fuel. Some households also occasionally burn biomass for heating during the monsoon.

\section{Intervention}

Our intervention took advantage of a government-led rapid expansion of access to LPG through a programme known as Pradhan Mantri Ujjwala Yojana (Prime Minister's Brightness Scheme, or PMUY).${ }^{24-26}$ PMUY provided 80 million households with LPG connections as of September 2019. PMUY removes some of the barriers to LPG access by covering the cost of the LPG cylinder deposit (1600 Indian rupees or US\$23), regulator and hoses, and small administrative fees. It also provides a no-interest loan for purchase of an LPG stove.

Our intervention supplemented the package of benefits provided by the government through PMUY. In our study, each household was given a sturdier two-burner stove than the one typically sold to beneficiaries of the PMUY programme. Furthermore, as national safety standards require the stove to be placed above the cylinder, we provided a stone and metal table to hold the stove to each participating household. All households paid for fuel at the national subsidised price (about 480 Indian rupees or $\sim \mathrm{US} \$ 7$ per $14.2 \mathrm{~kg}$ cylinder).

In a parallel study we conducted in this area, we found that we could be more successful in discouraging chulha (traditional stove) use if households had a second cylinder of fuel. A second cylinder is important to ease supply issues, as refills can take many days to be fulfilled due to logistical challenges. Provision of a second cylinder helps ensure continuous LPG supply and can discourage chulha use. Thus, we lent each household a second LPG cylinder. As the study was coming to an end, field staff asked participants if they would like to pay the deposit on the second cylinder within 6 months of receiving it, in a maximum of three instalments. If the participants did not pay the deposit of 1600 Indian rupees (US\$23), field staff asked them to return the second cylinder at the end of the study. Having two cylinders is common practice in many urban areas in India, but rare in poor rural communities.

We requested (but did not require) that all households disable their chulha by dismantling it, moving it outdoors or filling it with rocks. This request clarified that the main health purpose of provision of free LPG stoves was to stop use of smoke-producing chulha. Although chulhas are easily re-enabled (rebuilt, removing rocks, etc), it was a meaningful act that directly linked our goals with concrete actions of the households. We kept stove-use monitors (SUMs), described below, on the disabled chulhas to check whether cooks used the chulhas when we were not present.

\section{Recruitment and study timeline}

We trained and provided a small incentive (200 Indian rupees, $\sim \mathrm{US} \$ 3$ ) to local community health workers known as Accredited Social Health Activists (ASHAs) to identify newly married women who might be eligible for our marriage-based intervention programme. ASHAs are volunteers from the community who create health awareness and provide a link between the community and the formal public health system. They are responsible for encouraging local health planning and increasing utilisation and accountability of the public health system. ASHAs are typically aware of events occurring in the community, like marriages.

We requested that ASHAs identify women who were currently using biomass for cooking, were married in the last 45 days and who did not smoke. Participating households helped our study staff identify other recently married couples. In addition, some newly married couples approached study staff and indicated willingness to participate. We visited all participants-those identified by ASHAs, through communication with households, and those who voluntarily approached study staff-and confirmed their eligibility for recruitment. We conducted an informed consent process where we explained the study objectives and study procedures and obtained signed consent forms from all participants before recruiting them.

During the initial recruitment visit to each household with a newlywed couple, fieldworkers administered informed consent and placed thermocouple-based SUMs on the primary chulha. Typically, the ASHA who identified the participant was present during this visit. Field staff collected a baseline survey on the second visit. This visit occurred at the same time that the LPG distributors' 'mechanics' delivered and installed the stove and gas cylinder and trained the women on its use. Two LPG distributors provide LPG service in the areas; both work for Hindustan Petroleum Corporation, with whom we collaborated. Our field staff equipped stoves with additional thermocouple SUMs on each LPG burner.

\section{Tracking pregnancies}

Field staff visited participants' homes every 15 days to download data from SUMs. During this visit, fieldworkers asked participants if they had been tested for pregnancy since the last visit. If a participant responded 'Yes,' fieldworkers would contact the respective ASHAs and government nurses who would confirm the pregnancy and the date of the first day of the last menstrual period. We estimated the conception date as 14 days after the recorded last menstrual period. We added 9 months and 7 days to the recorded last menstrual period to estimate the expected delivery date. ${ }^{27}$

\section{Stove usage monitoring}

Usage of both the chulha and the LPG stove was assessed using a type of SUM, in this case a battery-powered, thermocouple temperature data logger (Wellzion SSN-61, 
Xiamen, Fujian, China) as described in Pillarisetti, et al. Briefly, we placed thermocouple probes on LPG burners in a standard location underneath each burner. Probes for chulhas were placed $1-2 \mathrm{~cm}$ from the edge of the combustion zone and cemented into place using the same mud that the stove is made from. We programmed loggers to record an instantaneous temperature in degrees Celsius every 5 min.

We translated temperature data into days of use by examining daily temperature ranges and the daily maximum temperature measured by each sensor on each day. Use-days included any day with a temperature range greater than or equal to $30^{\circ} \mathrm{C}$ and a maximum temperature above $60^{\circ} \mathrm{C}$. After the intervention began, field staff also observed the status of the primary chulh $a$ during every visit. They noted signs of use, including if it was warm or in active use, whether or not it was filled in or dismantled, or if it had been moved outside.

\section{LPG refill information}

We calculated the frequency of LPG refills in two ways. First, in collaboration with the local LPG distributors, we maintained logs of request dates for cylinder refills. Second, we followed up with households to ensure that they had indeed made a refill request and that the distributor had fulfilled the request. Information for each household was maintained in a separate binder or paper file. Data entry staff entered data into an Excel spreadsheet weekly, where it was verified by the field manager and a data entry specialist. Findings are in the online supplemental information.

\section{Data analyses}

All data handling and descriptive and statistical analyses were performed in R V.3.5 (R Foundation for Statistical Computing, Vienna, Austria). Non-parametric Wilcoxon tests were used to compare distributions of stove usage and days of pregnancy coverage. Details of transforming raw stove use monitoring data into metrics of stove use have been described in detail previously. ${ }^{28}$

\section{Participant and public involvement}

Participants were not directly involved in the design of this project, as it was based on a national programme. However, the community from which participants were drawn assisted in review and revising of the messaging used to promote the intervention.

\section{RESULTS}

Participant and household characteristics are in table 1. All approached newlywed couples agreed to participate. We approached 54 couples in total; 2 were lost to follow-up due to migration and 2 already had an LPG connection (including this attrition, $93 \%$ of those approached were enrolled and maintained). In the previously published pregnancy study, we approached 55 households and recruited $52(95 \%)$. Households in

\begin{tabular}{|c|c|c|}
\hline Characteristic & $\begin{array}{l}\text { Marriage } \\
\text { study } \\
(n=50)\end{array}$ & $\begin{array}{l}\text { Pregnancy } \\
\text { study } \\
(n=52)\end{array}$ \\
\hline Mean age (SD) & $20.5(1.7)$ & $24(2.28)$ \\
\hline Mean years of education (SD) & $10(2.3)$ & $7(2.98)$ \\
\hline Non-nuclear homes* (\%) & 72 & 65 \\
\hline \multicolumn{3}{|l|}{ Religion (\%) } \\
\hline Hindu & 98 & 98 \\
\hline Buddhist & 0 & 2 \\
\hline Others & 2 & 0 \\
\hline $\begin{array}{l}\text { Median annual income in } \\
\text { Indian rupees (US\$) }\end{array}$ & $30000(420)$ & $25000(350)$ \\
\hline \multicolumn{3}{|l|}{ Household income source (\%) } \\
\hline Work in own farm & 0 & 0 \\
\hline Work in others' farms & 100 & 98 \\
\hline Others & 0 & 2 \\
\hline $\begin{array}{l}\text { Median number of meals } \\
\text { cooked per day }\end{array}$ & 2 & 2 \\
\hline $\begin{array}{l}\text { Median number of } \\
\text { household members }\end{array}$ & 5 & 5 \\
\hline \multicolumn{3}{|l|}{ Fuel used for cooking (\%) } \\
\hline Firewood only & 13.7 & 5.7 \\
\hline Firewood and dung & 86.2 & 92.3 \\
\hline$\%$ that heat bath water daily & 100 & 100 \\
\hline
\end{tabular}

*Nuclear households are comprised of a married couple or a man or a woman living alone or with unmarried children (biological, adopted or fostered) with or without unrelated individuals. Other household arrangements are defined as non-nuclear.

this marriage study were recruited, on average, 40 days after marriage (SD 21). The gap between recruitment and introduction of the LPG intervention was substantial (68 days on average, SD 30). This gap was due to delays in receiving LPG connections from the two LPG distributors, due to factors beyond the study's control. Table 2 and figure 2 summarise the time between critical study points, including recruitment and marriage, LPG deployment and recruitment, and between marriage and LPG deployment. LPG refill data are available in online supplemental table S1.

\section{Pregnancies and potential days of pregnancy-protection}

Approximately 1 year after enrolment into this study, 25 $(50 \%)$ of women had become pregnant. Among those who became pregnant, the mean and median dates of conception were 115 and 79 days after marriage, respectively, with a range of 17-373 days. Eighteen (36\%) women delivered within 1 year of enrolment into the study.

Eleven pregnant participants $(44 \%)$ received their interventions prior to conception, as planned. Largely due to logistical challenges with the LPG distributors, our 


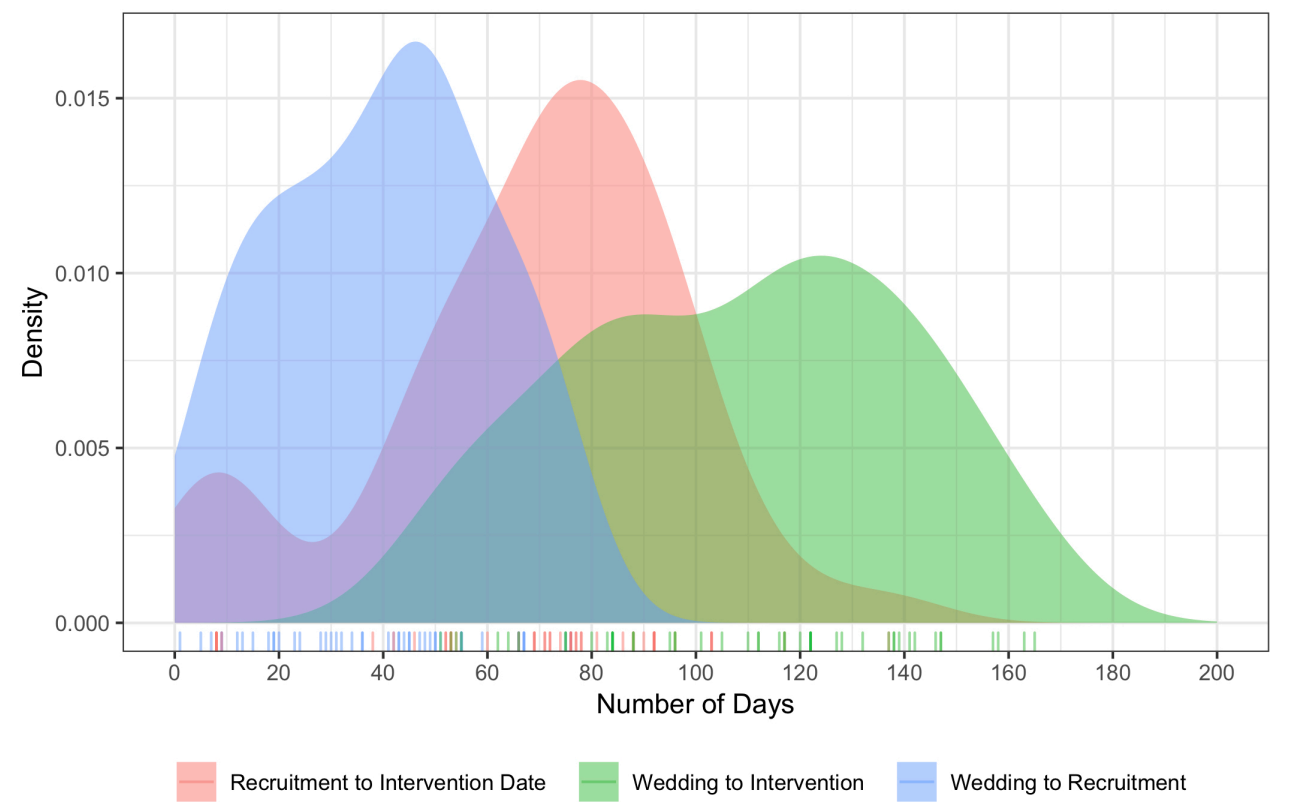

Figure 2 Time in days between significant study events. Much of the delay in providing interventions to newlywed couples was related to challenges with the distribution system, depicted in pink.

intervention did not cover $100 \%$ of the pregnancy for 14 of the 25 participants who became pregnant. These participants were enrolled in the study on average 40 days (SD 21) after marriage, indicating that we were able to recruit newlyweds fairly quickly. Unfortunately, they did not receive their LPG intervention until an average of 76 days (SD 18) post-enrolment.

For this subsample, the intervention began an average of 63 days (SD 35) post-conception. Although we intervened later after marriage than ideal for these 14 women, 11 of them received the intervention during the first trimester. The remaining three received interventions between the 14th and 16th weeks of pregnancy.

Many of the participants did not get pregnant $(n=25)$ or, of those that did get pregnant, did not deliver $(n=7)$ by the end of the study. These participants and their households had coverage with the LPG intervention prior to and throughout their ongoing or future pregnancies.

\section{Stove usage}

We collected approximately 12.5 million datapoints, representing around 46500 stove-days of data. The current analysis is restricted to 14 days prior to intervention and

\begin{tabular}{lcccccc}
\hline \multicolumn{6}{l}{ Table 2} & Time in days between significant study events \\
\hline Measure & Average & SD & Min & Median & Max \\
\hline $\begin{array}{l}\text { Wedding to } \\
\text { recruitment }\end{array}$ & 40 & 21 & 1 & 43 & 76 \\
$\begin{array}{l}\text { Recruitment to LPG } \\
\text { intervention }\end{array}$ & 68 & 30 & 8 & 73 & 137 \\
$\begin{array}{l}\text { Wedding to LPG } \\
\text { intervention }\end{array}$ & 109 & 32 & 51 & 112 & 165 \\
\hline
\end{tabular}

LPG, liquefied petroleum gas.
300 days post-intervention; data outside of these windows are sparse. We reduced stove usage data into three categories-days with any LPG use, with exclusive LPG use and with any chulha use. A visual depiction of time trends of usage in these categories is in figure 3 ; see also table 3.

The fraction of days with any chulh $a$ use pre-intervention was, as expected, significantly different than the fraction of days with any chulha use post-intervention $(\mathrm{p}<0.05)$. There was a strong, negative linear trend between the fraction of homes using LPG and time since introduction of the intervention (approximately $2.9 \%$ reduction per month, $\left.\mathrm{r}^{2}=0.68 ; \mathrm{p}<2 \times 10^{-16}\right)$.

\section{Disabling chulhas and purchasing second cylinders}

The field staff returned for observations 2-3 weeks after the study ended. At that time, 19 (38\%) of indoor chulhas were still in use; the rest were voluntarily disabled or left unused. Of the original 50 participants recruited, 44 $(88 \%)$ paid the deposit in cash to purchase the second cylinder we loaned them.

\section{Comparison with previous work recruiting at pregnancy}

In our previous study, ${ }^{28}$ we recruited a group of pregnant women $(n=52)$ through the routine surveillance performed by ASHAs. This group received the same intervention package as in this marriage-based study. In that study, the average pregnant woman was recruited 19 weeks (SD 5) after conception, substantially later in pregnancy than participants in the current study who became pregnant (mean=10 weeks, SD 13, n=25, Wilcoxon rank sum test, $\mathrm{p}<0.001)$. Given an expected duration of pregnancy of 40 weeks, the marriage recruitment covered approximately 10 additional weeks, or $25 \%$ more time, than recruiting at pregnancy-even with the handicap of delayed delivery of LPG interventions. 


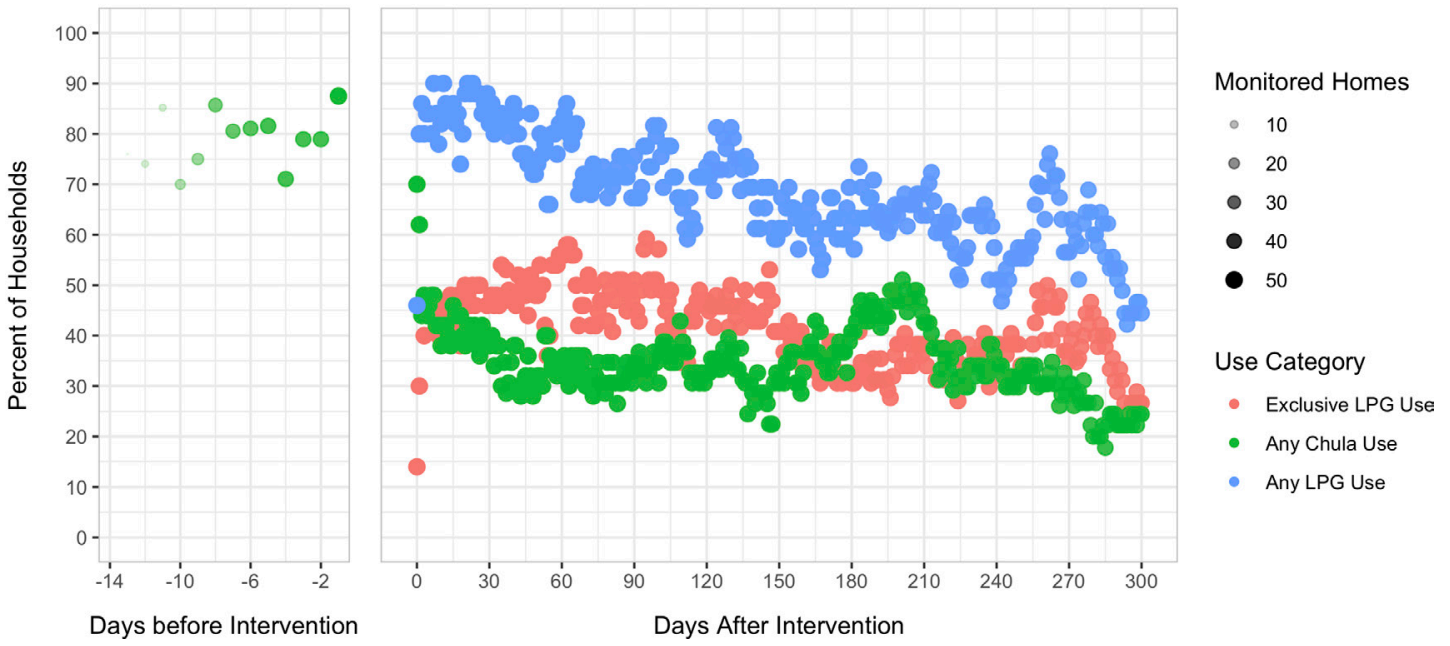

Figure 3 Trends in exclusive LPG use, any LPG use and any chulha use. The size and opacity of the points indicate the number of households monitored on each day (larger and darker points are a larger number of homes). Exclusive LPG use occurs on days when only LPG is used for cooking; any chulha use includes days with either exclusive use of the chulha or stacking of LPG and the chulha. Similarly, 'any LPG use' refers to days with exclusive LPG use or with stacking. LPG, liquefied petroleum gas.

Among women who delivered their babies, those in the current study $(\mathrm{n}=18)$ had the LPG intervention for 211 days on average (SD 46), substantially more than the average of 120 days (SD 42) in the previous study $(\mathrm{n}=50$, Wilcoxon rank sum test, $\mathrm{p}<0.001)$. Among the women who became pregnant but did not deliver during our study $(n=7)$, preconception coverage occurred for, on average, 133 days (SD 52) and presumably for their entire pregnancies. Table 4 includes summary statistics comparing the current study with the core intervention group from the previous study.

\section{DISCUSSION}

We recruited 50 newly married couples in rural Maharashtra, India into an LPG intervention with the goal of providing additional days of pregnancy protection from household air pollution exposure by intervening prior to conception. To the best of our knowledge, this is the first demonstration of recruitment at marriage for a household energy intervention, and one of the few recruiting at the time of marriage for any health intervention. We used ASHA community health workers to recruit married couples; there are nearly 1 million ASHAs throughout India, providing a potential method to scale up this type of recruitment. We provided each participant with an intervention consisting of an LPG stove, two LPG cylinders (the second on loan), a platform to raise the cooking surface off the ground and messaging related to the benefits of cooking with clean fuels. We additionally encouraged households to disable their chulha by dismantling it, filling it with rocks or moving it outdoors.

Although we were able to recruit newlyweds within, on average, 40 days of their wedding, we were unable to intervene immediately after recruitment due to logistical issues with local LPG distributors. Regardless, this intervention is novel in its attempt to recruit newly married couples shortly after marriage and shows that this approach is feasible; the few past health interventions in India working with a similar population have more broadly targeted married couples. ${ }^{23} 29$ Our findings indicate that existing infrastructure, like ASHAs, can be used to identify newlyweds, and to potentially speed up delivery of household energy and other interventions.

Table 3 Days with intervention, with valid monitoring, and with exclusive use of LPG after intervention

Days

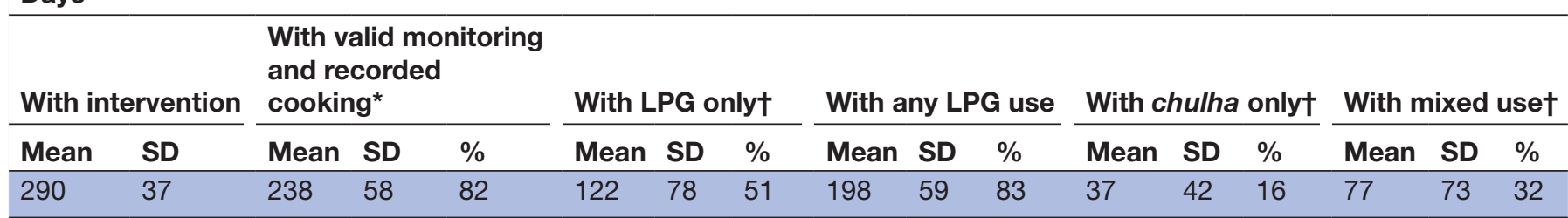

*Valid monitoring days are after LPG installation where data are present either from SUMs or based on fieldworker observations. †The per cent in each category is 100 times the average number of days divided by the average number of days with valid monitoring and recorded cooking.

LPG, liquefied petroleum gas; SUMs, stove-use monitors. 
Table 4 Pregnancy days covered by the intervention

\begin{tabular}{|c|c|c|c|c|c|c|c|c|c|c|}
\hline & \multicolumn{5}{|c|}{ Marriage } & \multicolumn{5}{|c|}{ Core intervention } \\
\hline & Mean & SD & Min & Max & $\mathbf{N}_{\mathrm{p}}$ & Mean & SD & Min & Max & $\mathbf{N}$ \\
\hline \multicolumn{11}{|l|}{ Days between intervention+conception* } \\
\hline After conception† & 63 & 35 & 5 & 115 & 14 & & & & & \\
\hline Days with intervention before conception & 92 & 71 & 2 & 210 & 11 & & & & & \\
\hline
\end{tabular}

*Negative values indicate the number of days that the intervention was deployed prior to the imputed date of conception. †Intervention deployed after conception.

$\mathrm{N}_{\mathrm{p}}$, number of participants

Half of our participants were pregnant within a year of their wedding, with 18 deliveries by August 2018. Of those who were pregnant and delivered, the average time with intervention was approximately 210 days; for those who did not get pregnant, the time with intervention until the end of the study was, on average, 293 days. Among those who got pregnant but did not deliver by the study end, the average duration of time with the intervention was 400 days (SD 50). A programme targeting marriage does, thus, provide additional coverage with clean fuels to households that do not conceive shortly after marriage. Some of the days of intervention coverage could be considered 'non-essential' - that is, days with the intervention outside of pregnancy. However, that coverage-assuming use of LPG and displacement of cooking with biomassprovides benefits to other children and adults living in the household. Future studies could further explore the number of days of coverage during pregnancy versus those without pregnancy to evaluate potential costs of our proposed intervention strategy.

Pregnancies were tracked by our field team in two ways: by calling ASHAs and asking about updates and by being in regular contact with households. Larger studies may need to establish alternate methods of verifying pregnancy. We also note that the methods we relied on for estimating conception and delivery date rely on recall and are otherwise uncertain; given that all participants' conception and delivery dates were estimated in the same way, we do not think this approach affected our comparisons between groups.

Few households used LPG exclusively. LPG did, however, displace some chulha-based cooking. When we lent a second fuel cylinder to households, LPG supply was more reliable, and it was easier to arrange refills. Eighty-eight per cent of households were willing to pay the deposit in order to retain the second cylinder, indicating its popularity and utility. Similarly, asking, but not requiring, households to disable their chulha was moderately successful, with $31 \%$ of households complying. Households could re-enable their chulha when fieldworkers left the house.

Despite the popularity of the second cylinder and the moderate number of households that disabled their chulhas, exclusive usage of LPG was low. We have explored strategies to incentivise usage of clean stoves and fuels among pregnant women ${ }^{28}$ and among the general population. ${ }^{30}$ For example, when we offered a free trial for a second cylinder conditioned on disabling the indoor chulha, indoor chulha use ceased for the majority of homes (even after the free trial ended) ${ }^{30}$ It is worth testing this and other approaches for homes with newly married couples.

We also modelled a national programme targeting newly married couples using data from the 2015-2016 National Family Health Survey and targeting households that burned biomass. We looked at coverage during pregnancy, assuming that our programme did not face the logistical challenges we encountered. Such an exercise highlights the applicability of our recruitment approach beyond this pilot. Specifically, we looked at the interval between marriage and first birth. We examined births within 48 months of marriage, a period that includes $97 \%$ of all first births across India.

If we assume a stove programme could learn about new marriages and install an LPG stove within 3 months of the marriage, such an intervention would cover roughly $90 \%$ of the duration of first pregnancies. About $70 \%$ of these women would have the new stove for their entire first pregnancy-including all of their first trimester. The other $30 \%$ of first pregnancies would have the new stove for an average of $75 \%$ of their pregnancy. In contrast, an intervention targeting pregnancies instead of marriages would cover about $40 \%$ of each pregnancy, including none of the first trimester. In short, a pregnancy-based LPG intervention starting a month after learning about new marriages covers roughly twice as many weeks of pregnancy as a benefit that begins a month after learning about a new pregnancy.

Our results have implications for other components of antenatal care. For example, folic acid, anti-malarial bednets, antiparasiticals and iron have benefits during the first trimester, as well as earlier. Unfortunately, the healthcare system typically provides these products only after a pregnant woman visits a clinic. Targeting antenatal care after the healthcare system learns of the pregnancy ensures long periods of non-coverage of essential 
interventions. Some interventions, such as folic acid (a B vitamin crucial for development of the fetal nervous system), are especially important in the first trimester. ${ }^{31}$ Those providing antenatal services (especially in poor areas) should analyse if these services are more costeffective if provision started at marriage, instead of waiting until the healthcare system learns of a pregnancy.

\section{CONCLUSIONS}

Recruitment at marriage-through ASHAs and word-ofmouth-led to more weeks of protected pregnancy time than recruitment at pregnancy. On one hand, our sample is small and from one district. On the other hand, if replicated, this result has the potential to improve targeting of cookstove and other health interventions substantially. At scale, a stove intervention targeting marriage could cover roughly twice as many weeks of a first pregnancy as a programme relying on detecting pregnancy prior to intervention. To achieve this level of coverage, however, the intervention needs to provide LPG connections promptly after marriage.

It is also possible to combine interventions targeting both marriage and pregnancy. For example, there could be an intervention at marriage that promotes adoption of a safe stove and then provides free fuel during pregnancy. We piloted free fuel during pregnancy in a separate arm of our parallel study in the same area ${ }^{26}$ where we noted substantial adoption of LPG and reduction of chulha use. The pilot work performed here is informing a planned larger randomised controlled trial of these types of interventions evaluating their impact on low birth weight.

Our study provides evidence of the potential value of policies for maternal and child health that target newlyweds in rural areas. The cost to the government of the earlier, marriage-triggered intervention compared with one focused on pregnancy is largely the time value of money for a median of 1 year (until the start of the first pregnancy). There is also the cost of distributing stoves to the approximately $4 \%$ of women who do not become pregnant in their first 4 years of marriage. To the extent the government values covering women who are not pregnant and their households, the benefit-cost ratio improves further.

\footnotetext{
Author affiliations

${ }^{1}$ Gangarosa Department of Environmental Health, Rollins School of Public Health, Atlanta, Georgia, USA

${ }^{2}$ Vadu Rural Health Program, KEM Hospital Research Centre, Pune, India

${ }^{3}$ University of California, San Francisco, California, USA

${ }^{4}$ ICMR Center for Advanced Research on Air Quality, Climate and Health, Department of Environmental Health Engineering, Faculty of Public Health, Sri Ramachandra Institute of Higher Education and Research, Chennai, Tamil Nadu, India

${ }^{5}$ Haas School of Business, University of California, Berkeley, California, USA

${ }^{6}$ Savitribai Phule Pune University, Pune, Maharashtra, India

${ }^{7}$ Environmental Health Sciences, School of Public Health, University of California, Berkeley, California, USA
}

Twitter Rutuja Patil @ru2.patil
Acknowledgements We dedicate this paper to the memory of Professor Kirk R. Smith, pioneering health, energy and climate scientist, and an inspiration and teacher to us all. We thank the participants and their families for their patience and participation. We appreciate the hard work and dedication of our fieldworkers and generous cooperation of local ASHAs, District Health Officers, and the management and staff at Shah HP Distributor, Junnar and Gurudatta HP Gas Agency, Kolwadi. We acknowledge the help and guidance of Maria T Hernandez, Vijendra Ingole, and Ricardo Piedrahita.

Contributors AP, KB, SR, MG, AD, SS, RP, DIL, SJ and KRS designed the study. ND$S$ conceptualised the period of intervention and assisted with writing and reviewing the manuscript. SR, RP, AD, MG and AP led data collection, and received guidance from KB. AP, KRS and DIL conducted the statistical analyses and interpreted the data. KRS and AP drafted the manuscript. All authors reviewed, provided feedback and approved the final manuscript.

Funding This work was partly supported by the Implementation Science Network of the US National Institutes of Health (Z99 TW999999). AP was partially supported by HERCULES Center P30ES019776.

Map disclaimer The depiction of boundaries on the map(s) in this article does not imply the expression of any opinion whatsoever on the part of BMJ (or any member of its group) concerning the legal status of any country, territory, jurisdiction or area or of its authorities. The map(s) are provided without any warranty of any kind, either express or implied.

Competing interests None declared.

Patient consent for publication Not required.

Ethics approval Institutional Review Boards of University of California, Berkeley (2016-07-8968); KEM Hospital Research Centre Pune (KEMHRC/MHS/EC/1826) and Sri Ramachandra Institute of Higher Education and Research (IEC-N1/16/ NOV/56/79) approved this research and amendments to the initial protocol. All participants gave consent prior to enrolment in the study. Data were anonymised and privacy of all participants was ensured.

Provenance and peer review Not commissioned; externally peer reviewed.

Data availability statement The dataset used and analysed during the current study is available from KEM Hospital Research Centre on reasonable request.

Open access This is an open access article distributed in accordance with the Creative Commons Attribution Non Commercial (CC BY-NC 4.0) license, which permits others to distribute, remix, adapt, build upon this work non-commercially, and license their derivative works on different terms, provided the original work is properly cited, appropriate credit is given, any changes made indicated, and the use is non-commercial. See: http://creativecommons.org/licenses/by-nc/4.0/.

\section{ORCID iDs}

Ajay Pillarisetti http://orcid.org/0000-0003-0518-2934

Nadia Diamond-Smith http://orcid.org/0000-0002-8711-3029

Rutuja Patil http://orcid.org/0000-0001-6390-4363

\section{REFERENCES}

1 Bhutta ZA, Das JK, Rizvi A, et al. Evidence-Based interventions for improvement of maternal and child nutrition: what can be done and at what cost? Lancet 2013;382:452-77

2 Christian P, Khatry SK, Katz J, et al. Effects of alternative maternal micronutrient supplements on low birth weight in rural Nepal: double blind randomised community trial. BMJ 2003;326:571.

3 Vaidya A, Saville N, Shrestha BP, et al. Effects of antenatal multiple micronutrient supplementation on children's weight and size at 2 years of age in Nepal: follow-up of a double-blind randomised controlled trial. Lancet 2008;371:492-9.

4 Christiansen CS, Gibbs S, Chandra-Mouli V. Preventing early pregnancy and pregnancy-related mortality and morbidity in adolescents in developing countries: the place of interventions in the prepregnancy period. J Pregnancy 2013;2013:257546

5 Mullany BC, Becker S, Hindin MJ. The impact of including husbands in antenatal health education services on maternal health practices in urban Nepal: results from a randomized controlled trial. Health Educ Res 2007;22:166-76.

6 Prost A, Colbourn T, Seward N, et al. Women's groups practising participatory learning and action to improve maternal and newborn health in low-resource settings: a systematic review and metaanalysis. Lancet 2013;381:1736-46. 
7 International Institute for Population Studies. NFHS-4 (national family health Survey-4, 2017.

8 Amegah AK, Quansah R, Jaakkola JJK. Household air pollution from solid fuel use and risk of adverse pregnancy outcomes: a systematic review and meta-analysis of the empirical evidence. PLoS One 2014;9:e113920.

9 Klepac P, Locatelli I, Korošec S, et al. Ambient air pollution and pregnancy outcomes: a comprehensive review and identification of environmental public health challenges. Environ Res 2018;167:144-59.

10 Li X, Huang S, Jiao A, et al. Association between ambient fine particulate matter and preterm birth or term low birth weight: an updated systematic review and meta-analysis. Environ Pollut 2017;227:596-605.

11 Stieb DM, Chen L, Eshoul M, et al. Ambient air pollution, birth weight and preterm birth: a systematic review and meta-analysis. Environ Res 2012;117:100-11.

12 Smith KR, Bruce N, Balakrishnan K, et al. Millions dead: how do we know and what does it mean? methods used in the comparative risk assessment of household air pollution. Annu Rev Public Health 2014:35:185-206.

13 Alexander DA, Northcross A, Karrison T, et al. Pregnancy outcomes and ethanol Cook stove intervention: a randomized-controlled trial in Ibadan, Nigeria. Environ Int 2018;111:152-63.

14 Van Vliet EDS, Kinney PL, Owusu-Agyei S, et al. Current respiratory symptoms and risk factors in pregnant women cooking with biomass fuels in rural Ghana. Environ Int 2019;124:533-40.

15 Thompson LM, Valencia-Moscoso G, Peñaloza RA, et al. Does household air pollution from cooking fires affect infant neurodevelopment? developing methods in the NACER pilot study in rural Guatemala. Lancet Glob Health 2014;2:S18.

16 Dean S, Rudan I, Althabe F, et al. Setting research priorities for preconception care in low- and middle-income countries: aiming to reduce maternal and child mortality and morbidity. PLoS Med 2013;10:e1001508.

17 Kennedy E, Branca F, Webb P, et al. Setting the scene: an overview of issues related to policies and programs for moderate and severe acute malnutrition. Food Nutr Bull 2015;36:S9-14.

18 Ramakrishnan U, Grant F, Goldenberg T, et al. Effect of women's nutrition before and during early pregnancy on maternal and infant outcomes: a systematic review. Paediatr Perinat Epidemiol 2012;26 Suppl 1:285-301.
19 Dean SV, Lassi ZS, Imam AM, et al. Preconception care: nutritional risks and interventions. Reprod Health 2014;11 Suppl 3:S3.

20 Dean SV, Lassi ZS, Imam AM, et al. Preconception care: closing the gap in the continuum of care to accelerate improvements in maternal, newborn and child health. Reprod Health 2014;11 Suppl 3:S1.

21 Barker M, Dombrowski SU, Colbourn T, et al. Intervention strategies to improve nutrition and health behaviours before conception. Lancet 2018;391:1853-64.

22 Nguyen PH, Gonzalez-Casanova I, Young MF, et al. Preconception micronutrient supplementation with iron and folic acid compared with folic acid alone affects linear growth and fine motor development at 2 years of age: a randomized controlled trial in Vietnam. $J$ Nutr 2017;147:1593-601.

23 Daniel EE, Masilamani R, Rahman M. The effect of community-based reproductive health communication interventions on contraceptive use among young married couples in Bihar, India. Int Fam Plan Perspect 2008;34:189-97.

24 Smith KR, Sagar A. Making the clean available: Escaping India's Chulha Trap. Energy Policy 2014;75:410-4.

25 Sagar A, Balakrishnan K, Guttikunda S, et al. India leads the way: a Health-Centered strategy for air pollution. Environ Health Perspect 2016;124:A116-7.

26 Tripathi A, Sagar A, Smith K. Promoting clean and affordable cooking: smarter subsidies for LPG. Economic \& Political Weekly 2015;L:81-4.

27 Hall MH. Definitions used in relation to gestational age. Paediatr Perinat Epidemiol 1990;4:123-8.

28 Pillarisetti A, Ghorpade M, Madhav S, et al. Promoting LPG usage during pregnancy: a pilot study in rural Maharashtra, India. Environ Int 2019;127:540-9.

29 Santhya KG, Haberland N, Das A, et al. Empowering married young women and improving their sexual and reproductive health: effects of the first-time parents project. New Delhi: Population Council, 2008.

30 Harrell S. Essays in development, behavioral, and health economics. Chapter 1: Incentivizing elimination of biomass cooking fuels through a commitment mechanism and a spare LPG cylinder. Berkeley, CA: University of California, Berkeley, 2019.

31 De-Regil LM, Peña-Rosas JP, Fernández-Gaxiola AC, et al. Effects and safety of periconceptional oral folate supplementation for preventing birth defects. Cochrane Database Syst Rev 2015;12:CD007950. 